\title{
Effect of TIG Weld Current on 1Cr18Mn8Ni5N Austenitic Stainless Steel Welding Microstructure and Mechanical Properties Zhong-Bao HUANG ${ }^{1, a}$, Cheng-Gang YANG ${ }^{2, b,}{ }^{\text {, }}$, Nan-Song ZHENG ${ }^{3, c}$, Zhen LV $^{4, d}$, Hao-Yu BIN ${ }^{5, e}$ \\ ${ }^{1,2}$ Institute of Aeronautical Manufacturing and Engineering, Nanchang Hangkong University, NanChang \\ ${ }^{3,4,5}$ AVIC South Aviation Idustry co., Itd, ZhuZhou, HuNan \\ abaoban78@163.com, ${ }^{\text {b }}$ chgyang1977@163.com, ${ }^{\mathrm{C}}$ zhengns331@126.com, ${ }^{\mathrm{d}}$ Ivzhennf@sina.com, 564318806@qq.com \\ ${ }^{*}$ Corresponding author
}

Keywords: Austenitic Stainless Steel, Austenite, Pro-eutectoid Ferrite, Tensile Strength.

\begin{abstract}
Cr18Mn8Ni5N austenitic stainless steel is welded by the gas metal arc welding process to study the effect of three kinds of current on the microstructure and properties of welded joints. The experiment finds that the microstructure of weld metal is austenite and the morphology of austenite are thin strips, massive and coarse columnar in 162A, 170A, 178A, respectively. The microstructures of HAZ are austenite and pro-eutectoid ferrite. The joint comprehensive mechanical properties are the best when the current is $170 \mathrm{~A}$. The fracture mode of weld joints is fracture toughness.
\end{abstract}

\section{Introduction}

In order to reduce production costs, adding small $\mathrm{Mn}$ and nickel instead of nitrogen to produce a nickel-based stainless steel. The $1 \mathrm{Cr} 18 \mathrm{Mn} 8 \mathrm{Ni} 5 \mathrm{~N}$ steel belong $\mathrm{Cr}-\mathrm{Mn}-\mathrm{Ni}-\mathrm{N}$ type section of nickel austenitic stainless steel. This steel has good shaping and weldability compared with traditional $\mathrm{Cr}-\mathrm{Ni}$ austenitic stainless steel. This steel is widely used in aviation, aerospace, power plants, nuclear reactors and other engineering structures with serving in high temperature, high pressure and harsh conditions. The welded joints are usually more vulnerable parts in the metal components, so the mechanical properties of welded joints become major problems[1-5]. Currently, the welding method of $1 \mathrm{Cr} 18 \mathrm{Mn} 8 \mathrm{Ni} 5 \mathrm{~N}$ steel is mainly used TIG welding. The TIG welding process is a popular process in this area where a high degree of quality and accuracy is required. Moreover, TIG welding is more preferable than SMAW and MIG process because of the lower heat input[1]. The effect of welding current on the weld microstructure and mechanical properties of welded joints were studied, which was help to provide the basic application information for $1 \mathrm{Cr} 18 \mathrm{Mn} 8 \mathrm{Ni} 5 \mathrm{~N}$ stainless steel sheet welding.

\section{Material and Methods}

The material was $1 \mathrm{Cr} 18 \mathrm{Mn} 8 \mathrm{Ni} 5 \mathrm{~N}$ steel with solution treatment at $1100^{\circ} \mathrm{C}$, and the sheet size was $200 \mathrm{~mm} \times 100 \mathrm{~mm} \times 2.5 \mathrm{~mm}$, butt welding plate was used in this experiment. The welding wire was H0Cr19Ni11Mo3 and the welding wire diameter was $1.6 \mathrm{~mm}$. The main compositions of base metal and welding wires were showed in Table 1.

The equipment was orthogonal frequency arc DC TIG welding machine with pure argon gas protection and automatic filler wire.The welding parameters were showed in Table 2 Prior to welding, the specimens were thoroughly washed with acetone to clean greasy dirt and impurities. To study mechanical properties, the welded joint was sliced by abrasive cutter, and then machined into the required dimensions to get tensile specimens. In order to examine the microstructures of the welded joint, samples were prepared by cutting off weldment in the transverse direction. Samples were grinded by using silicon carbide waterproof electro coated abrasive papers. The tensile test 
was carried on the W9W-50 electronic universal testing machine, the samples were stretched under $2 \mathrm{~mm} / \mathrm{min}$. The samples were etched by corrosive $\left(\mathrm{HNO}_{3}: \mathrm{HCL}: \mathrm{H}_{2} \mathrm{O}=1: 1: 1\right)$. The microstructure was observed with 4XB-TV models inverted microscope. 401MVD digital micro-hardness tester was used to analysis micro-hardness distribution of the welded joints. The SEM was used to observe the fracture morphology of welded joints

Tab.1 Main chemical compositions of base metal and welding wires

\begin{tabular}{cccccccc}
\hline & $\mathrm{C}$ & $\mathrm{Si}$ & $\mathrm{Mn}$ & $\mathrm{Cr}$ & $\mathrm{Ni}$ & $\mathrm{N}$ & $\mathrm{Mo}$ \\
\hline 1Cr18Mn8Ni5N & 0.15 & 1.0 & $7.5-10.0$ & $17.0-19.0$ & $4.0-6.0$ & $\leqq 0.25$ & - \\
H0Cr19Ni11Mo3 & $\leqq 0.06$ & $0.3-0.7$ & $1.0-2.0$ & $18.0-20.0$ & $10.0-12.0$ & - & $2.0-3.0$ \\
\hline
\end{tabular}

Tab. 2 Welding process parameters

\begin{tabular}{ccccc}
\hline No. & Current/A & $\begin{array}{c}\text { Welding speed } \\
\mathrm{mm} / \mathrm{min}\end{array}$ & $\begin{array}{c}\text { Wiring speed } \\
\mathrm{mm} / \mathrm{min}\end{array}$ & $\begin{array}{c}\text { Gas flowing rate } \\
\text { L/min }\end{array}$ \\
\hline 1 & 162 & 260 & 820 & 15 \\
2 & 170 & 260 & 820 & 15 \\
3 & 178 & 260 & 820 & 15 \\
\hline
\end{tabular}

\section{Results and Analysis}

\section{Microstructures and Analysis}

The microstructure of weld metal was single austenite, the HAZ (heat-affected zone) were consisted of pro-eutectoid ferrite and austenite which were showed in figure 1-3. When the welding current was 162A, the microstructure of weld metal was small massive, elongated austenite and uneven distribution. When the current was 170A, the microstructure of weld metal was blocky austenite and uniform distribution. When the current was 178A, the microstructure of weld metal was coarse columnar austenite, and the austenite had strong directionality distribution.

Due to the austenitic stainless steel had small thermal conductivity, large thermal expansion coefficient, therefore it was difficult for the weld pool metal to radiate heat during welding[2-4]. When the current was 162A, 170A, 178A, respectively, the heating temperature of pool was gradually increased, thus the superheat of pool metal was successively larger and larger, resulting in weld metal got longer and longer residence time at high temperature. Therefore the austenite grain growth tendency was increased, so the austenite morphology in the weld were separately small block, strip, massive and columnar. Especially when the current was 178A, the superheat of the pool metal was maximum, the weld metal had the longest time to stay in high temperature and the grains had the largest growth tendency, thus the morphology of austenite was columnar in weld.

The figures 1 to 3 showed the weld didn't exit the ferrite phase, but the HAZ had pro-eutectoid ferrite. The different regions microstructure in HAZ had been showed in figure 4 .The morphology of pro-eutectoid ferrite was thin strips and distributed along the austenite grain boundaries. The content of ferrite in fusion zone was little. But the amount of ferrite increased significantly in fully recrystallization zone and the size of grain was fine. The amount of ferrite in incompletely recrystallization zone was least.

The precipitation and morphology of pro-eutectoid ferrite were pertinent to the composition of weld metal and cooling rate[6]. When the current were 162A,170A and 178A, the pool metal had long time to stay in high temperature and the cooling rate of pool was slow, the content of austenite stabilizing elements was in high level, thus the weld microstructure was single austenite phase. Due to the temperature of HAZ was lower than weld and the cooling speed was faster, when the HAZ was cooled from high-temperature to higher temperature $\left(770-680^{\circ} \mathrm{C}\right)$, the pro-eutectoid ferrite precipitated along austenite grain boundaries[6]. The welding thermal cycles lead to peak temperature was different in different zones of HAZ, resulted in the grain sizes of austenite was 
different and also lead to the precipitation and growth of pro-eutectoid ferrite were not at the same time in different regions of HAZ. Therefore the austenite grain sizes and pro-eutectoid ferrite content were different in HAZ.
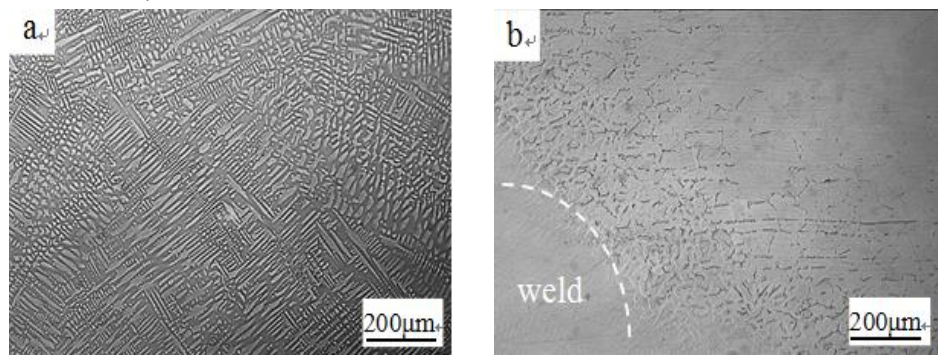

Fig.1 Joint microstructures of No.1: a-Weld.b-HAZ
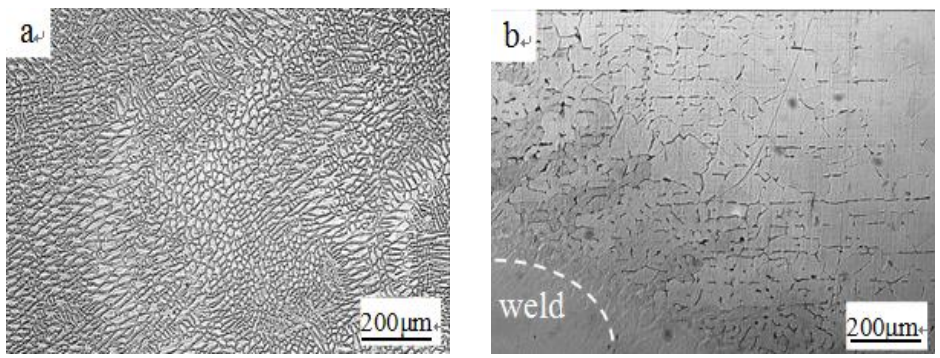

Fig.2 Joint microstructures of No.2: a-Weld.b-HAZ
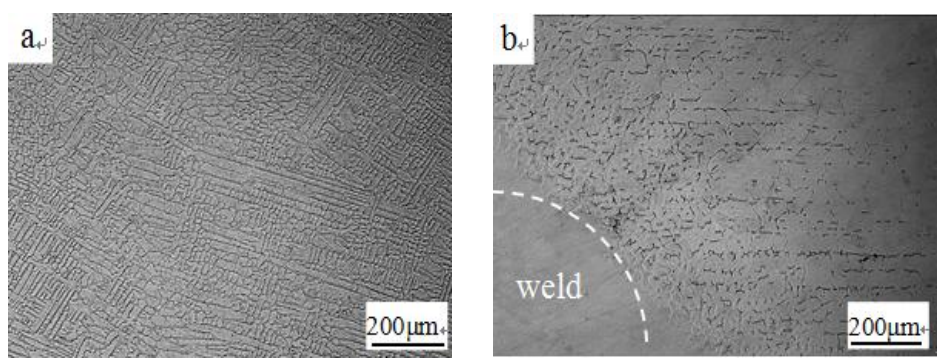

Fig.3 Joint microstructures of No.3: a-W.b-HAZ
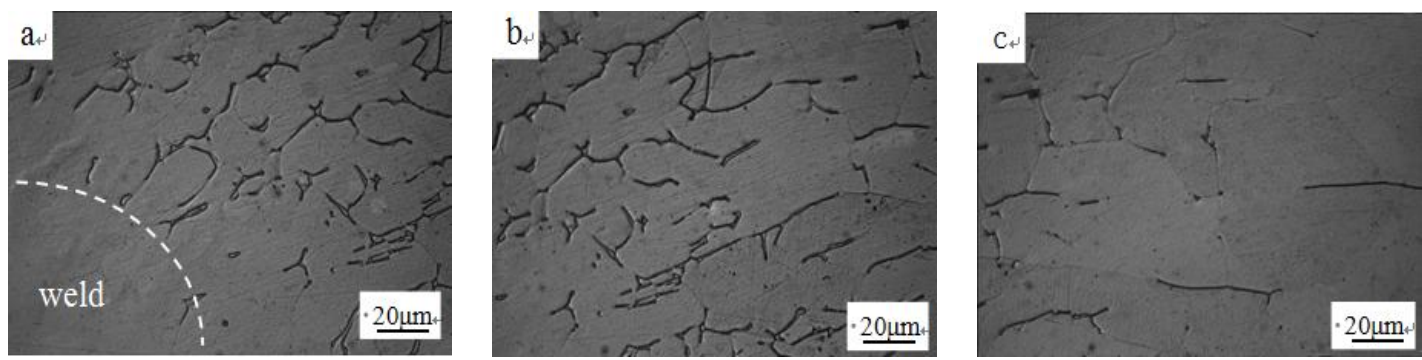

a-fusion zone.b-completed recrystallization zone.c-incompleted recrystallization zone

Fig.4 HAZ Microstructures of No. 3

\section{Tensile test of Welded Joints}

Data in table 3 showed that the tensile strength of welded joints in three kinds of current. When the welding current were $162 \mathrm{~A}, 170 \mathrm{~A}$ and $178 \mathrm{~A}$, respectively, the tensile strength of welded joints were $663.96 \mathrm{MPa}, 692.84 \mathrm{Mpa}$ and $610.34 \mathrm{MPa}$. When the current was $170 \mathrm{~A}$, the joint reduction of area were also higher.

According to the Hall-Petch formula, that the more the size of grains was finer and more uniform, the more the grain strength was higher and ductility was also better[7]. When the current were 162A or 178A,the austenite morphology in weld were small block, strip or coarse columnar, and 
distributed unevenly. Therefore the deformation was incoordinate in the stretching process, so the tensile strength and shaping of joints were lower than the strength of joint in 170A. When the current was 170A, the morphology of austenite was massive, thus the joint had the highest tensile strength. The fracture positions were all in weld, these suggested that the welding was the weakest area of welded joints.

Tab. 3 Tensile properties of welded joints

\begin{tabular}{cccc}
\hline No. & $\mathrm{R}_{\mathrm{m}} / \mathrm{MPa}$ & $\mathrm{A}_{\mathrm{t}} / \%$ & Joint strength coefficient $/ \%$ \\
\hline 1 & 663.96 & 21.40 & 0.819 \\
2 & 692.84 & 21.30 & 0.855 \\
3 & 610.34 & 19.58 & 0.753 \\
\hline
\end{tabular}

\section{Hardness Test of Welded Joints}

The micro-hardness distribution curves of $1 \mathrm{Cr} 18 \mathrm{Mn} 8 \mathrm{Ni} 5 \mathrm{~N}$ steel welded joints were showed in figure 5. As can be seen, the micro-hardness of the weld was the lowest. The micro-hardness of the zone which near the fusion line was the highest, with distance from the fusion line increased hardness was gradually decreased. The micro-hardness of weld of No.2 was the stablest.

The $1 \mathrm{Cr} 18 \mathrm{Mn} 8 \mathrm{Ni} 5 \mathrm{~N}$ steel had many alloy elements to increase micro-hardness by dissolved solid matters. The weld was single austenite phase and hadn't solid solution strengthening, so that the hardness of weld was minimum. The pro-eutectoid ferrite reduced the micro-hardness of HAZ. As mentioned earlier, when current was $170 \mathrm{~A}$, due to the weld grains distributed more uniform than the others so the hardness of weld had small fluctuation.

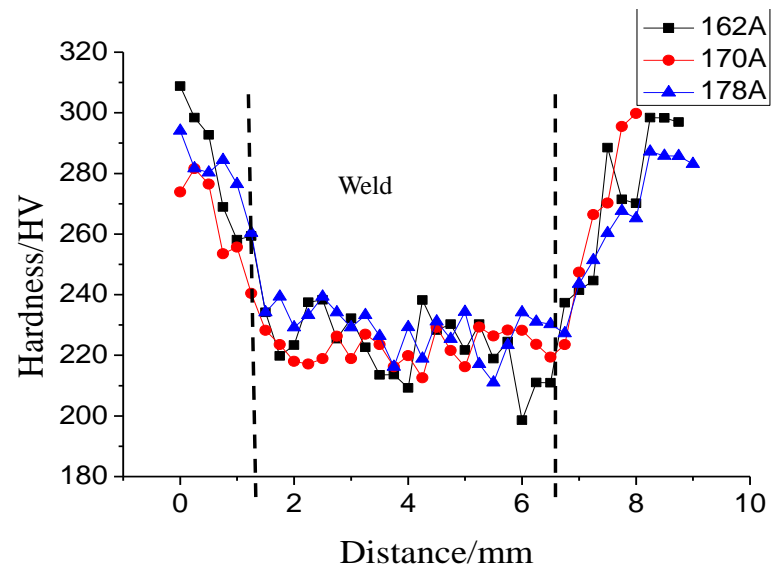

Fig. 5 Micro-hardness distribution of welded joints

\section{Fracture Mode}

Figure 6 showed that the fracture mode of joints was fracture toughness, The dimple was equiaxed and its sizes were same and distributed uniform. Some dimple was deeper. These indicated joint had good shaping and toughness. The dimple didn't exit particulate matter and these suggested the welded joint didn't exit low melting point eutectic.

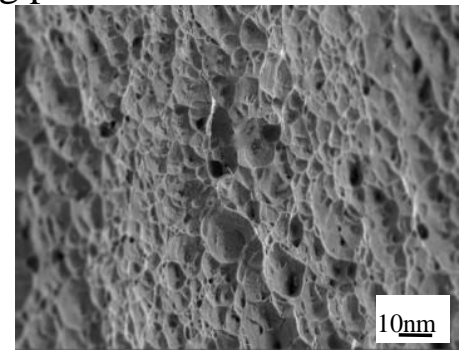

Fig. 6 Joint fracture of No.2 


\section{Conclusions}

(1)When the current respectively were $162 \mathrm{~A}, 170 \mathrm{~A}$ and $178 \mathrm{~A}$ by the gas metal arc welding process, the microstructure of weld metal was single austenite, the HAZ were consisted of pro-eutectoid ferrite and austenite

(2) The joint had the best comprehensive mechanical properties when the current was 170A.

(3)The fracture mode of weld joints was fracture toughness and the dimple were equiaxed in fracture.

\section{References}

[1]E.Ahmadi, A.R. Ebrahimi, Welding of 316L Austenitic Stainless Steel with Activated Tungsten Inert Gas Process ,J. Journal of Materials Engineering and Performance. 24(2015) 1065-1071.

[2]Liu Feng, Huang Hua, Liu Yujiao, Study on Weldability of TIG Welded Joint of 1Cr18Ni9Ti Austenitic Stainless Steel, J. Hot Working Technology. 40(2011) 141-145.

[3]Man Dahu, Wang Lifang, Weld Hot Cracking causes and Preventive Measures of Austenitic Stainless Steel, J. Hot Working Technology. 41(2012) 181-184.

[4] Sheng Guoxiong, Liu Bin. Effect of Nitrogen on Structure and Mechanical Properties of 304 Austenitic Stainless Steel, J. Journal of Iron and Steel Research. 9(1997) 33-36.

[5] Yang Gang, Liu Zhengdong, Cheng Shichang,et.al. Effect of Nitrogen Content on Mechanical Property of Forged 0Cr19Ni9N Stainless Steel, J. Journal of Iron and Steel Research. 15(2003) 34-37.

[6]Zhang Hanqian. Steel welded joints Metallurgy, Machinery Industry Press, Beijing, 2000, pp. 132-145.

[7]Cui Zhongyin. Metallurgy and Heat Treatment Theory, Harbin Institute of Technology Press, Harbin, 2007, pp. 159-160. 